\title{
Protection and enlightenment of ecological integrity of Canadian national parks
}

\author{
Shuhui Yang ${ }^{1}$ and Xiaoyu Duan ${ }^{1, *}$ \\ ${ }^{1}$ College of Landscape Architecture, Sichuan Agricultural University, Chengdu 611130, China
}

\begin{abstract}
Canada is one of the first countries in the world to establish a national park, and pioneered the concept of ecological integrity management of national parks. Based on this concept, the country has basically achieved the sustainable development of national parks. China has a vast territory, a large number of scenic spots and nature reserves, but its system and management methods need to be optimized. This paper takes forestry developed countries as an example, summarizes the progress of ecological integrity protection in Canadian national parks, summarizes its current ecosystem adaptive management concepts and implementation methods, Ecological Integrity (EI) monitoring construction and related evaluation index systems, ecosystem protection and restoration. The experience is intended to provide a reference for the improvement of the ecological integrity protection of national parks in China.
\end{abstract}

\section{Progress in ecological integrity protection Introduction}

Canada has a vast territory with 46 national parks, with a total area of about $328,200 \mathrm{~km}^{2}$, accounting for about $3 \%$ of the country's land area [1]. National parks established under the National Parks Act of Canada, owned by the government and managed by the Parks Canada Agency (PCA). PCA has the world's richest experience in ecological integrity management and monitoring and is recognized as the world leader in the development of ecological integrity guidelines [2], mainly through the application of research, monitoring, active management and recovery activities to protect the ecological integrity of national parks [3]. Since 1990, Canada's national parks have entered a perfect stage aimed at protecting the ecological integrity [4], which has been committed to protecting the biodiversity, structural and functional integrity of its ecosystem and maintaining the sustainable development of the ecosystem.

As early as 1979, Canada introduced the term "ecological integrity" into the park policy. Further definitions of "maintaining ecological integrity" were made in the 1994 Parks Canada Guiding Principles and Operational Policies. Under the theme of "ecological protection", the policy clarifies that protection of commemorative integrity and ecological integrity are the most important principle for the management and operation of Canadian parks [5]. Nearly 20 years after the introduction of ecological integrity, Canada has established a panel to recommend how best to ensure that ecological integrity is maintained across the system of national parks in 1998. In its 2000 report, the Panel proposes the definition of ecological integrity as [6]:"An ecosystem has integrity when it is deemed characteristic for its natural region, including the composition and abundance of native species and biological communities, rates of change and supporting processes." The Canada National Parks Act, as amended in 2000, followed this concept. In 2001, the federal government passed legislation to define ecological integrity as the top priority of Canadian national parks [7], and ecological integrity changed from a policy goal to a legal requirement [8]. In the 2005 September Report of the Commissioner of the Environment and Sustainable Development, it is mentioned that through good monitoring, ecological restoration and public education programs are essential for Canada to protect or restore the ecological integrity of the park and to raise public awareness. At the same time, Parks Canada Agency has proposed to maintain and improve the ecological integrity of national parks as a long-term goal, and has developed a series of policy measures around it, including the construction of an ecological integrity monitoring and reporting system and the development of the latest park management improvement plan [9]. It is worth noting that the above policy measures were completed before 2008. From 2005 to 2014, Canada carried out national park ecological integrity maintenance operations and identified a number of maintenance and restoration projects, including the establishment or replacement of biological pathways, control of the number of surplus species, and regulation of the fire cycle. During the implementation of the project, PCA established a comprehensive ecological integrity protection and recovery action framework with local communities, stakeholders, park visitors, and achieved some milestones, including:

- Maintenance actions make ecological integrity the core of park management.

*Corresponding author: 13645273@qq.com 
- Maintenance actions have promoted partnerships between PCA and indigenous peoples and other industries.

- The maintenance initiative initiated a public education project to promote public participation.

- New park management plan standards have been developed in the maintenance operations.

- The maintenance operations implemented ground protection and restoration projects.

According to The State of Canada's Natural and Historic Places 2011, 92\% are reported to be in either good (nearly $50 \%$ ) or fair condition in $59 \%$ of the national parks that PCA has assessed (102 ecosystems), and 8\% ecosystems are assessed as being in poor condition, $43 \%$ of the ecosystems that have been rated as passing have a downward trend, and the challenge of ecological integrity protection is intensified [10].

In 2017, Canada conducted EI monitoring of 42 national parks (118 ecosystems). In the EI monitoring and evaluation report, $63 \%$ were in good condition, $20 \%$ were in fair condition, and $17 \%$ were in poor condition [11]. The results of the assessment indicate that most of the national park ecosystems are stable (81 out of 118), 23 have improved trends, and 14 have downward trends [11]. The report is based on the latest available information for each park ecosystem, mixing data from 0 to 10 years. In 2011, compared with the 2017 ecological integrity assessment, the national park ecosystem showed an overall improvement trend, which proved that Canada's ecological integrity protection and recovery actions in the past few years have achieved certain results. In 2018, the A natural priority - A report on Parks Canada's Conservation and Restoration Program introduced the actual cases of protection and restoration of 40 national parks that are being completed or completed, and listed some of the results that have been achieved so far, covering everything from forest restoration to the conservation of endangered flora and fauna, from elk population control to the mitigation of threats to invasive species [12]. This series of policies, research and development measures have made valuable contributions to the sustainable development of the ecological integrity of national parks.

\subsection{Ecosystem management}

Ecosystem management is an important part of the national park management plan and an important means to achieve ecological integrity, providing a conceptual and strategic basis for the protection of park integrity. PCA has established an ecological monitoring system, and through the analysis and evaluation of national park monitoring results to develop an ecosystem management plan, the use of adaptive management methods for ecosystem protection and restoration to achieve ecological integrity protection goals. The management plan is not for management purposes. It provides a framework for subsequent management, planning and implementation within this framework. In the management of ecosystems, PCA mainly considers eight factors [13]:
- Ecological integrity is assessed by understanding the evolutionary history of the region.

- National parks are part of the natural ecosystem and must be managed in an integrated manner.

- The population of species should reach the minimum number of surviving populations.

- Ecosystems have characteristic succession, and understanding the speed and direction of their succession is critical to understanding the system.

- National parks have limited capacity, and human development and use time should be coordinated with park ecosystem protection.

- Ecological integrity must be assessed and understood within the landscape.

- Ecological integrity can be better protected by maintaining or restoring native genetic, species and community diversity in the area.

- The conservation strategy should maintain or restore key ecological processes that reflect its natural conditions.

When research confirms that the structure or function of the ecosystem has undergone severe changes and can only be improved through human recovery, it can be actively managed using human disturbance. PCA defines active management as a positive intervention for achieving the desired state of the ecosystem or its components. These measures include reintroduction of species, fire management, remediation of contaminated sites, control of invasive species, etc. It has successfully reduced the pressure on the park ecosystem and effectively preserved the ecological integrity of the national park. Ecological restoration is considered to be a form of active management, and ecological restoration practices include the concept of adaptive management. The essence of implementing an adaptive management approach is to conceive experiments for recovery projects and to build an ecosystem model that predicts the specific outcomes of the proposed recovery measures, including impacts on other parts of the ecosystem, and is positive for helping managers make effective decisions. The current focus of PCA's ecosystem management is on biodiversity conservation to achieve the 2020 Canadian biodiversity target. As of 2013, approximately $10 \%$ of terrestrial territories and approximately $1 \%$ of marine territories in protected areas of Canada are protected, and at least $17 \%$ of terrestrial and $10 \%$ of marine protection is expected to be completed by 2020 to address ecosystem degradation.

\subsection{Ecological monitoring system}

\subsubsection{Ecological integrity monitoring}

Ecological integrity monitoring is an important tool for national park management. When the native species, landscape and function of the ecosystem are intact, the ecosystem have integrity [11]. Canada's Ecological Integrity (EI) monitoring officially began in 2008 and is an important part of national park management. All parks in the country have developed a five-year monitoring plan as the basis for applying for project funding. The monitoring plan describes the park's ecosystem 
conceptual model, monitoring measures, monitoring project protocols and sampling design. Adherence to EI monitoring is a top priority in the Canada National Parks Act [14]. Through EI monitoring, people can understand the specific plants, animals and their ecosystems in the park, and master the changes of various species in the ecosystem at a certain time scale. EI monitoring provides national park managers with data on ecological integrity changes. By monitoring representative components of national park ecosystems, such as forests, freshwater and wetlands, the ecological integrity of national parks can be assessed to report changes and trends in ecological integrity of individual parks [9]. It is the key method for measuring the state of national parks in Canada [11]. Well-designed EI monitoring programs can provide the following valid information [15]:

- Assess the effectiveness of management measures;

- Increase understanding of ecosystem changes;

- Find areas for further research;

- As an "ecological baseline", compare unprotected landscapes.

Canada issued the EI Monitoring Framework as early as 2005 as a set of criteria for assessing the ecological integrity of national parks and continues to this day. The EI monitoring framework divides the ecological integrity of a national park into three parts, namely biodiversity, ecosystem functions and stressors, as shown in Table 1 [15].

Table 1. Indicators for assessing the ecological integrity of national parks.

\begin{tabular}{|c|c|c|}
\hline $\begin{array}{c}\text { Biodiversity } \\
\text { (characteristic of } \\
\text { region) }\end{array}$ & $\begin{array}{l}\text { Ecosystem } \\
\text { functions } \\
\text { (resilient, } \\
\text { evolutionary } \\
\text { potential) }\end{array}$ & $\begin{array}{c}\text { Stressors } \\
\text { (unimpaired } \\
\text { system) }\end{array}$ \\
\hline $\begin{array}{l}\text { Species richness: } \\
\text { - change in } \\
\text { species richness } \\
\text { - numbers and } \\
\text { extent of exotics } \\
\text { Population } \\
\text { dynamics: } \\
\text { - } \\
\text { mortality/nativity } \\
\text { rates of indicator } \\
\text { species } \\
\text { - immigration/ } \\
\text { emigration of } \\
\text { indicator species } \\
\text { - population } \\
\text { viability of } \\
\text { indicator species } \\
\\
\text { Trophic structure: } \\
\text { - size class } \\
\text { distribution of all } \\
\text { taxa } \\
\text { - predation levels }\end{array}$ & $\begin{array}{c}\text { Succession/ } \\
\text { retrogression: } \\
\text { - disturbance } \\
\text { frequencies and } \\
\text { size (fire. insects, } \\
\text { flooding) } \\
\text { - vegetation age } \\
\text { class distributions } \\
\text { Productivity: } \\
\text { - remote or by } \\
\text { site } \\
\text { Decomposition: } \\
\text { - by site } \\
\text { Nutrient } \\
\text { retention: } \\
\text { - Ca, N by site }\end{array}$ & $\begin{array}{l}\text { Human land-use } \\
\text { patterns: } \\
\text { - land use maps, } \\
\text { roads densities, } \\
\text { population } \\
\text { densities } \\
\text { Habitat } \\
\text { fragmentation: } \\
\text { - patch size, } \\
\text { inter-patch } \\
\text { distance, forest } \\
\text { interior } \\
\text { Pollutants: } \\
\text { - sewage, } \\
\text { petrochemicals, } \\
\text { etc. } \\
\text { - long-range } \\
\text { transport of } \\
\text { toxics } \\
\text { Climate: } \\
\text { - weather data } \\
\text { - frequency of } \\
\text { extreme events } \\
\text { Other: } \\
\text { - park specific } \\
\text { issues }\end{array}$ \\
\hline
\end{tabular}

National parks develop their own specific monitoring measures and indicators based on this framework.
Currently, Canada requires each national park to undergo an EI monitoring program adjustment to ensure that the revised monitoring plan monitors the ecosystem integrity of the entire park based on management objectives and the EI monitoring framework. The main challenge facing each park is to analyse and summarize regional and national-level monitoring indicators to develop core monitoring indicators related to the park.

\subsubsection{Ecological integrity assessment}

The Canadian national parks status report (including the ecological integrity assessment report) is published every five years prior to the development of a new park management plan and is the primary tool for communicating the results of ecological integrity monitoring [16]. The ecological integrity indicator can indicate the current status and development trend of the national park ecosystem, and is also a summary of the ecosystem monitoring score. The results of the ecological integrity assessment are used to develop appropriate park management plans, determine ecosystem management and recovery guidelines, and provide data support for priority funding support. The PCA defines 12 ecosystem types across the country for assessing ecological integrity. Each national park has selected four to eight indicators based on the major ecosystems of a particular park, such as forest, tundra, grasslands, freshwater or wetlands ecosystems. In 2009, the PCA reported 180 indicators for 42 national parks. In 2011, it became 177 indicators (129 in the south national park and 48 in the north national park). In 2017, Canada reported on the status and trends of 118 indicators in 42 national parks. The ecological integrity assessment is based on wildlife survey data, plant productivity estimates, water quality measurements and invasive species survey data, which are derived from field site sampling, satellite imagery, academic and government partners. The aggregated ecological integrity report, each indicator of ecological integrity is represented by a trend arrow (increasing, decreasing or stable levels of integrity) and a traffic light symbol: green for "acceptable" ecological integrity, yellow indicating a "concern" and red indicating "impaired" condition requiring management action [16]. And each evaluation condition is assigned a score based on its threshold (good $=2$, fair $=1$, poor $=0$ ). The threshold is determined by long-term monitoring results or expert opinions or expected goals. If one-third or more of the measures are scored poor, the ecosystem-level indicator is also scored poor. If less than one-third of the measures are scored poor, the average score (weighted equally) of the measures determines the ecosystem score [11]. The assessment of the overall trends in the major ecosystems is based on data changes in the first five years. In the case where most indicators have non-repetitive validity, the system is considered to be stable if the results of the ecosystem indicator assessment have not changed. 


\section{Experience in ecosystem conservation and restoration}

In recent decades, Canada has been committed to maintaining the ecological integrity of national parks, facing various ecological challenges, and has accumulated rich experience and obtained many effective ecosystem protection and restoration methods. It has obtained international recognition (that is, the basis for the 2012 IUCN Guidelines on ecological restoration for protected areas), which has effectively realized the restoration of ecosystem functions, and has achieved a balance between local cultural preservation and natural ecological restoration.

\subsection{Finding a partner to promote project implementation}

The national park of Canada has sought partners to advance the implementation of ecological conservation and restoration projects and has divided them into national partners, regional partners and local partners. At the national level, PCA has partnered with the Vancouver Aquarium to encourage Canadian citizens to clean up the national park's shoreline debris and to protect and restore the ecological integrity of the coastline. PCA also works with institutions such as Destination Canada (DC), The Royal Canadian Geographical Society, Indigenous Tourism Association of Canada (ITAC) and other institutions to enhance its influence, protect natural resources and improve local economic conditions. At the regional level, PCA collaborates with provincial tourism marketing organizations, national park protection associations and other organizations to create connections between people and national parks through ecological monitoring, visitor experiences, concerts and other events to attract young people to become future stewards of national parks. At the local level, PCA collaborates with local universities, community non-profit associations, conservation organizations, non-profit research institutions, educational institutions and other groups to improve public education, gain further research and monitor results, restore risky species, strengthen natural cultural resource management, etc.

\subsection{Paying attention to ecological monitoring and improve management}

Through the continuous exploration of new technologies and methods to build a national park ecological monitoring network, and constantly improve the existing monitoring system to provide effective information for the further management of national parks. For example, park managers use web cameras, remote cameras and drones to capture wildlife population information. They also used a genetic identification method called "life barcode" to investigate insect diversity in national parks. In addition, a list of major plant and animal species in each park is maintained and continuously updated to regularly conduct a survey of park ecosystem types to assess the distribution and status of the park ecosystem. At the same time, in order to assess the follow-up recovery of the national park ecosystem protection and restoration project, after the completion of the project, a series of monitoring plans were also formulated and implemented.

\subsection{Effective human control and restoration of endangered species}

National parks use artificial breeding to restore endangered species in ecosystems. For example, Fundy National Park releases large quantities of farmed adult salmon into rivers for natural spawning, bringing wild salmon back to the area. They also artificially removed alien invasive grasses and sowed nursery-grown seed into prepared habitat to increase rare plant populations in Gulf Islands National Park [17]. In addition, park managers improve the quality of habitats at risk by constructing ecological corridors and artificial nest habitats, directing wildlife to niche and mitigating the impact of road traffic on ecosystems. For example, the installation of deflection fences in the Bruce Peninsula National Park introduces wildlife into safe passages to protect the diversity of wildlife on the Bruce Peninsula. Restoring damaged forests by controlling the number of wild animals, such as killing moose in Gros Morne National Park to control its population, protecting the growth of young trees and restoring forest health.

\subsection{Economic and practical innovative ecological restoration method}

In 2018, A report on Parks Canada's Conservation and Restoration Program proposed some economically effective methods to achieve ecological restoration. The specific measures are as follows [12]:

- Determine the preferred areas for vegetation restoration in national parks based on conservation biology through the use of GIS;

- Use fire as a tool to protect the national park ecosystem.

Parks Canada Agency's Conservation and Restoration Program (CoRe), $29 \%$ of projects use controlled sources of fire to restore species and ecosystems [12]. They believe that human suppression of fire actually interferes with the natural ecological process. For mountain parks, in the absence of regular fires, the vegetation community that adapts to the fire will be reduced, the diversity of wildlife habitats will be reduced, the forests will become vulnerable to disease, and the possibility of catastrophic wildfires will increase. Planning a fire is the safest way to restore ecological functions. Fires have shaped landscapes in Canada and around the world, and many ecosystems have evolved and renewed with fire. From 2015 to 2017, Canada implemented nine carefully planned "fires" in the mountain forests of four national parks to restore ecosystems, such as 135 hectares in Kootenay, 733 hectares in Jasper, 1,360 hectares in Banff and 68 hectares were restored in Revelstoke [12]. 


\subsection{The participation of the public and stakeholders plays an important role}

National Parks gain public and stakeholder understanding and support for ecosystem conservation and restoration projects by recruiting volunteers, negotiating with local residents, communicating with relevant companies, and adopting science education. The participation of the public and stakeholders has reduced the opportunities for species invasion, promoted the harmonious coexistence of humans and wildlife, and weakened the impact of human activities on the national park ecosystem. These measures played an important role in the operation of the project. Canada also encourages the public and stakeholders to contribute their knowledge, skills, economic power and supervisory power to actively participate in the management of national parks.

\section{Enlightenment and suggestion for the construction of national parks in China}

China's national park construction has just started, lack of experience in ecological integrity protection, and faces problems such as legal system construction, ecosystem management, ecological monitoring system construction, ecosystem protection and restoration project implementation, which have affected the protection, utilization and sustainable development of natural resources in national parks in China. Learning from the experience of ecological integrity protection in Canadian national parks, we can give full play to the important role of relevant government agencies, the public, relevant stakeholders and other groups to promote the sustainable and healthy development of national parks.

\subsection{Accelerate the construction of the legal system of national parks}

At present, China has set up 10 national park system reform pilots, and has successively introduced relevant national park master plan. Although some national parks have proposed local protection and management regulations, unified national park legislation is still missing. Local laws and regulations do not meet the protection needs of the national park ecosystem integrity, and require national-level legislative co-ordination [18]. The primary goal of the Canada National Parks Act is to protect ecological integrity, establish the status and responsibilities of the PAC, and introduce a series of regulations and regulations in accordance with the Act, covering national park species protection, infrastructure, fire protection, operations, etc. The national park has carried out a single legislation, and has formulated management plans on a regular basis, forming a relatively complete legal system. At present, China's national parks implement a central and local coordinated management mechanism. When conditions are ripe, the ownership of all-natural resource assets of the national parks can be gradually transferred to the direct exercise by the central government [19]. Accelerating national park legislation and introducing regulations and regulations on species protection, operation, fire safety, and industrial development in the relevant parks will help to divide the central and local responsibilities, help establish the main status of the National Park Administration, and give full play to the overall planning of the bureau. The role is conducive to the protection of ecological integrity, to achieve ecological protection, there are laws to follow, and violations of law must be investigated.

\subsection{Establish a national park ecological monitoring system}

In recent years, China has carried out monitoring surveys on hydrology, meteorology and natural resources, and has obtained some monitoring data and research results, but has not formed a comprehensive and improved monitoring network system [20]. Canada has a wellestablished system for ecological monitoring and assessment, from monitoring to discovering problems to planning solutions, so that the revision of the national park management plan can follow the results of the ecological integrity assessment. The construction of China's national park ecological monitoring system is still in the exploratory stage. The establishment of an ecological monitoring system needs to be carried out according to the actual situation in China. The specific implementation can be carried out in several steps:

- Based on an in-depth analysis of the types of national park ecosystems, China's ecological integrity assessment indicators should be established.

- National parks should innovate and learn from frontier ecological monitoring methods, identify major pressure sources inside and outside the park, and develop management plans and evaluation criteria based on monitoring results.

- Park managers should regularly report the ecological integrity of the park, update and formulate management plans, and create a national park ecological monitoring system with Chinese characteristics.

\subsection{Strengthening ecosystem adaptive management}

Ecosystem adaptive management is a dynamic management process that monitors, evaluates and continuously adjusts and optimizes management plans on a timely basis based on changes in ecosystems over time [21]. Based on long-term ecosystem monitoring, Canada identified major stress factors inside and outside the national park and targeted ecosystem decompression actions to manually restore ecosystems that have caused significant structural and functional changes. In the pilot stage of national park construction, China has initiated ecological corridor construction, alien species removal, and bald mountain ecological management to promote the restoration of national park ecosystems [22]. There is still a long way to go in the construction of national parks in China. It is necessary to analyse and determine the main pressure factors of various types and regional parks as soon as possible, establish an ecosystem model, clarify the changes in ecosystems, and constantly adjust 
management plans. Learning from the frontier ecosystem restoration methods, economically and effectively protect the ecological integrity of national parks, such as fire recovery, species control and so on.

\subsection{Promote social synergy and public participation}

China's national parks should achieve ecological integrity protection under the principle of state ownership, universal public welfare and universal sharing. It requires not only the government's efforts, but also the contribution of the public. The management of protected areas in China has always been subject to territorial management, with little public participation, and there are fewer opportunities for public participation in the construction of national parks at this stage. The National Park has established a partnership management mechanism for government, enterprises, social organizations and relevant stakeholders in Canada, providing funds, science and technology, manpower and other resources for ecological integrity protection. They strengthened communication with the public, stakeholders and ecological protection education, encouraged them to join the protection of national parks, reduced the risk of human damage, and promoted the implementation of ecological protection and restoration projects. China can take the following measures to achieve the ecological integrity protection of national parks:

- China can play the leading role of the government, establish a safeguard system and a partnership mechanism, and promote cooperation between relevant industries, institutions, universities, protection organizations and other organizations.

- China can promote the construction of ecological protection science education and information disclosure platform, and strengthen the education of ecological integrity protection.

- China can provide as many public participation opportunities as possible, such as setting up campus volunteer inspectors, visitor behaviour manager managers, recovery action volunteers and other volunteer service positions in ecosystem monitoring and recovery to provide social power for national park ecological integrity protection.

- China can implement the economic compensation policy of the public's personal outstanding deeds and institutional (individual) ecological protection actions, and mobilize the enthusiasm of the whole people.

\subsection{Promote the construction of smart national parks}

With the continuous development of big data, mobile internet, cloud computing and other information technologies, all fields are actively promoting smart management and service construction. Smart park refers to the intelligent response to the needs of the service population by effectively utilizing the Internet of Things (IOT) to enhance the operational management of national or urban parks [23]. In terms of national park ecological protection, "wisdom" is mainly reflected in the application of real-time intelligent environmental monitoring systems (temperature, humidity, air pressure, carbon dioxide, etc.), drone bio-monitoring, Internet of Things applications (automatic collection of ecological data, automatic monitoring of parks), smartphone applications (virtual rangers) and other technologies. The national park of Canada uses Google technology to launch a virtual tour feature service that allows Internet users to immerse themselves in the beauty of national parks through electronic devices such as smartphones, tablets, VR devices and other electronic devices. At present, the construction of smart national parks is still in the exploratory stage around the world. China can use its advanced information technology to innovate national park protection technologies and measures, and to be smart in park management operations, ecological monitoring and tourist services, actively taking the international forefront.

\section{Acknowledgments}

This work was supported by the 2017 Sichuan Agricultural University double support program (03572602), the 2018 Sichuan Agricultural University double support program (03573245) and the 2019 Sichuan Agricultural University Social Science Research Project (2019PTYB04).

\section{References}

1. Parks Canada Agency, 2018. https://www.pc.gc.ca/en/pn-np/cnpn-cnnp/cartemap-txt. (accessed on 11 March 2019)

2. Z. Wurtzebach, C. Schultz, BioScience 66, 446457(2016)

3. Office of the Auditor General of Canada, 2013. http://www.oag-

bvg.gc.ca/internet/English/parl_cesd_201311_07_e_ 38677.html. (accessed on 16 May 2019)

4. Y. Zhang, World Agriculture 4, 139-144(2018)

5. Minister of Canadian Heritage, 1994. http://parkscanadahistory.com/publications/principle s-policies-e-1994.pdf. (accessed on 20 February 2019)

6. Parks Canada Agency, 2000. http://publications.gc.ca/collections/Collection/R62323-2000-1E.pdf. (accessed on 29 February 2019)

7. S. Fluker, 2009. https://papers.ssrn.com/sol3/papers.cfm?abstract_id =1329094. (accessed on 05 March 2019)

8. J . Benidickson, 2013. https://papers.ssrn.com/sol3/papers.cfm?abstract_id $=2296254$. (accessed on 08 March 2019)

9. Office of the Auditor General of Canada, 2005. http://www.oagbvg.gc.ca/internet/docs/c20050900ce.pdf. (accessed on 11 March 2019) 
10. Parks Canada Agency, 2011. https://www.pc.gc.ca/en/docs/pc/rpts/elnhcscnhp/2011/part-b\#toc5-2. (accessed on 11 March 2019)

11. Environment and Climate Change Canada, 2018. https://www.canada.ca/content/dam/eccc/documents /pdf/cesindicators/ecological-integrity-of-nationalparks/2018/Ecological-integrity-national-parksen.pdf. (accessed on 11 March 2019)

12. Parks Canada Agency, 2018. https://www.pc.gc.ca/en/agence-agency/biblib/rapports-reports/core-2018. (accessed on 20 March 2019)

13. Parks Canada Agency, 2018. https://www.pc.gc.ca/en/nature/science/conservation /ie-ei. (accessed on 11 March 2019)

14. R.T. Mcmullin, D. Ure, M. Smith, H. Clapp, Y.F. Wiersma, Ecological Indicators 81, 214-221(2017).

15. Parks Canada Agency, 2017. https://www.pc.gc.ca/en/nature/science/controlemonitoring/ecosysteme-ecosystem. (accessed on 19 May 2019)

16. S. Woodley, The George Wright Forum 27, 151160(2010)

17. Parks Canada Agency, 2018. https://www.pc.gc.ca/en/agence-agency/biblib/rapports-reports/core-2018/ouest-west/ouestwest10. (accessed on 19 March 2019)

18. C. Liu. Guarantee the construction of national parks by legal system[N]. People's Daily, (2019)

19. National Forestry and Grassland Administration, 2017. http://www.forestry.gov.cn/main/195/content1031519.html. (accessed on 23 April 2019)

20. T. Wang, F. Gao, B. Wang, P.L. Wang, Q.H. Wang, H.L. Song, C.L. Yin, Journal of Glaciology and Geocryology 39, 229-234(2017)

21. Y.N. Zheng, Q. Jia, Y.J. Zhang, Journal of Beijing Forestry University (Social Sciences) 16, 21-26(2017)

22. J.H. Li, From national parks to park countries[N]. CPPCC Daily, (2019)

23. E. Truch, J. Sutanto, Smart Parks report, (2018) 